\title{
Produções Científicas de Educação em Direitos Humanos: uma revisão integrativa
}

\section{Scientific productions in Human Rights Education: a integrative review}

\author{
Stella Arantes Aragão*, Adilson Pereira**. \\ *Centro Universitário de Volta Redonda, ** Pontifícia Universidade Católica
}

\begin{abstract}
Resumo
A presente pesquisa tem objetivo de analisar diferentes produções científicas em Educação em Direitos Humanos $(\mathrm{EDH})$ no Brasil em um período delimitado de tempo. Também tem como meta analisar a EDH no contexto social brasileiro, afim de compreender elementos de sua historicidade que auxiliem em práticas para uma melhor eficiência no trato do assunto, dentro e fora das instituições formais, bem como tentar compreender quais são as percepções dos autores acerca desse viés pedagógico e quais são as áreas de conhecimento que tratam do assunto e quais as implicações que isso resulta, tanto na teoria quanto na prática da EDH.
\end{abstract}

Palavras-chave: Revisão integrativa, Direitos Humanos, Educação em Direitos Humanos

\begin{abstract}
The following research aims to analyze different scientific productions in Human Rights Education in Brazil within a delimited period of time. It also aims to analyze HRE in the Brazilian social context, in order to understand elements of their history that assist in their use for a better efficiency in dealing with the subject, inside and outside the formal institutions, as well as to try to understand what are the authors' perceptions about the pedagogical bias and what are the areas of knowledge that deal with the subject and what are the implications of this, both in theory and practice of HRE.

Keywords: Human Rights, Integrative Review, Human Rights Education
\end{abstract}

\section{A Educação em Direitos Humanos no Brasil}

A relevância da Educação em Direitos Humanos (EDH), atualmente, é alicerçada em sua universalidade e no cuidado que instituições internacionais e domésticas dão aos seus objetivos. No entanto, há um movimento atual, promovido principalmente pela mídia e pela parcela conservadora da sociedade, que visa promover um conceito distorcido do que são os direitos humanos, atrapalhando no desenvolvimento da educação dos indivíduos para a vida em coletividade. Visto que os direitos humanos são uma matéria de suma importância para a compreensão da ética, o aluno que bem compreende seus conceitos está mais propenso para uma convivência harmoniosa dentro da sociedade.

Dessa forma, esse processo deve ser compreendido dialeticamente; afinal, haveria uma transmutação desses conceitos ao nível do senso comum e sua compreensão junto aos jovens educandos não se torna clara por força da ausência do conhecimento teórico-prático e dos estados relativos de alienação a que os jovens estariam submetidos

\section{Porque é importante estudar EDH no Brasil}

O estudo dos direitos humanos vem assumindo importância para a construção de uma sociedade mais igualitária. Em contrapartida, os veículos midiáticos não raramente reforçam estereótipos que atrasam os avanços que a academia se esforça em construir. Assim sendo, a revisão integrativa da produção científica é no sentido de compreender um pouco sobre a cientificidade da EDH, suas características e suas propostas.

A EDH conquistou espaço em várias etapas e instituições de ensino, desde o ensino fundamental até a formação continuada. Os conceitos dos direitos humanos dialogam com várias instituições e aspectos sociais, como a política, a economia, e as questões sociológicas e históricas.

Na tradição histórica do Brasil, que tem como herança uma extrema desigualdade social, étnica e de gênero, o estudo e aplicação dos direitos humanos se torna mais urgente. Maria Victoria Benevides afirma que se trata de uma mudança cultural especialmente importante no Brasil, que é oriundo de valores e costumes que foram herdados de uma tradição histórica pautada fatores históricamente construídos, como a escravidão, a política oligárquica e patrimonial, o sistema de ensino autoritário e elitista, a complacência com a corrupção, o descaso com a violência, o sistema familiar patriarcal e machista, a sociedade racista e preconceituosa contra todos os considerados diferentes, o desinteresse pela participação cidadã e pelo associativismo solidário, o individualismo consumista (Benevides, pg. 310, 2003).

Estes elementos fazem parte de uma análise sucinta que detalha alguns dos pontos pelos quais a herança de violação dos direitos humanos sobrevive na sociedade brasileira. O desrespeito aos direitos mais básicos e fundamentais não apenas sobrevivem, mas são legitimados pelas instituições e assegurados pela parcela conservadora da sociedade.

As demandas sociais, que usualmente são pautadas pelos movimentos sociais, são uma forma de construção 
de assuntos que necessitam uma atenção maior para a busca da igualdade. No Brasil, os maiores exemplos de movimentos sociais que galgaram avanços são o movimento negro, o movimento da comunidade LGBT e o movimento feminista. Outros exemplos também são importantes de serem lembrados, como as conquistas históricas dos direitos trabalhistas.

Mesmo com a ratificação de vários tratados e convenções internacionais em direitos humanos, as violações dentro do território brasileiro são recorrentes. À essa questão estão atrelados aspectos sociais, enraizados historicamente, que dão legitimidade às violações que, por vezes, passam despercebidas aos olhos da sociedade. Sobre o assunto, Frei Betto argumenta que ainda atualmente varios países têm seus aparatos jurídicos fundamentados nos direitos inalienáveis a todos, mas que ainda sim não é asegurada à toda população uma vida justa e digna, o que faz com que esas Constituções não valham muito (Betto, Pg. 2, 1993).

A preocupação em assegurar que os meios materiais de se atingir a igualdade entre todos é um dos assuntos que mais concerne ao estudo dos direitos humanos atualmente. Se não há um esforço em construir de fato os meios que possibilitam a justiça e a igualdade, os instrumentos meramente formais e legais se tornam supérfluos.

Cresce também no Brasil o número de programas de pós graduação específicos em direitos humanos. Em uma breve procura por programas de pós graduação em direitos humanos no Google, encontra-se na primeira página da busca: o Programa de Pós-Graduação em Direitos Humanos da Universidade Federal de Pernambuco; o Programa de Pós-Graduação em Direitos Humanos e Políticas Públicas da PUCPR; o Programa de Pós-Graduação em Direitos Humanos da Universidade Federal da Paraíba e o Programa de Pós-Graduação em Direitos Humanos da Universidade de Brasília. Além destes, também é possível encontrar diversos cursos de Pós-Graduação, inclusive com educação à distância.

Muitos destes programas se preocupam com as questões sociais, étnicas, de igualdade de gênero, de acesso à cidade, de tolerância religiosa e de justiça social. A interdisciplinaridade dos direitos humanos é o que auxilia para que toda essa gama de assuntos sejam pautadas em seu contorno.

\section{A alienação na educação e as estratégias pedagógicas}

A EDH, como meio pedagógico, também se encontra em estado de alienação. Primeiramente, ela é alienada pelos próprios instrumentos jurídicos que dificultam a acessibilidade, tanto de forma física quanto de forma axiológica. Em segunda instância, ela é alienada pelos veículos de massa que divulgam e propagam estereótipos e conceitos errôneos do assunto.

A educação em direitos humanos, logo, possui um duplo caminho. O primeiro se situa no âmbito formal da educação, ou seja, o espaço escolar, sendo este espaço um local institucionalizado que visa reproduzir a sociedade tal como ela existe (Severino, Pg. 72, 2001). O segundo, está localizado fora das instituições formais, e, como colocado por István Mészáros, felizmente este segundo caminho não pode ser controlado e manipulado pela estrutura formal legalmente salvaguardada e sancionada (Mészáros, Pg. 53, 2008). Logo, a educação precisa capacitar os docentes para intervir no mundo.

A capacidade de intervir ou não no mundo não é uma escolha do professor, posto que a própria manutenção e reprodução da ideologia dominante já é, por si só, uma forma de intervenção, bem como o seu desmascaramento, do outro lado (Freire, Pg. 35 2015). A escolha do educador em realizar seus esforços para a intervenção na sociedade, então, precisa decidir entre uma consciência de mundo e do que necessita mudança ou uma alienação daquilo que contribui com a ordem social.

Seguindo a mesma lógica, Antônio Joaquim Severino vai dissertar que "a educação pode criticar e superar esses conteúdos ideológicos e assim atuar na resistência à dominação da sociedade, contribuindo para relações político-sociais menos opressoras" (Severino, 2001, Pg. 75), ou seja, a educação pode se tornar prática transformadora.

O importante pensador das estruturas sociais, Antônio Gramsci, descreve a ideologia como sendo o maior instrumento para cimentar valores em uma população de dominados. A ideologia é um conjunto de consensos que servem para perpetuar a aceitação de estruturas impostas, sem o uso da coerção, posto que esta é deixado ao Estado (Gramsci, 1968, Pg.10 e 11) Sendo assim, a educação se torna uma das engrenagens para que o grupo dominante consiga exercer, reafirmar e manter sua hegemonia. $\mathrm{O}$ poder exercido pela escola no funcionamento de um sociedade é enorme, e por isso, o incentivo às práticas educativas compromissadas com por fim (ou, ainda, diminuir) com as mazelas sociais é muito importante para a construção de uma comunidade que lute contra a desigualdade social e suas consequências políticas, sociais, económicas, culturais e jurídicas.

\section{Metodologia}

O presente trabalho opta pela pesquisa qualitativa, mais especificamente o método de pesquisa bibliográfica por meio de uma revisão de publicações de revistas que abordam especificamente a educação em direitos humanos. É relevante ressaltar que a escolha pelas publicações leva em consideração a especificidade do tema e não a quantidade de acessos ou as qualificações recebidas pelas revistas. A opção pelo método está ligada à importância dos resultados da revisão bibliográfica, por vezes negligenciados por uma constante escolha de pesquisas de campo.

Segundo Casiraghi (2010) "a tarefa do pesquisador que desenvolve uma pesquisa nesses moldes é apresentar uma análise do panorama de um determinado assunto". Nesse sentido, fica claro que a revisão bibliográfica possui enorme importância para a produção de conhecimento e, nesse caso, para a produção de estratégias que auxiliam docentes no ensino de direitos humanos no Ensino Médio.

Com o advento da internet e a constante democratização do acesso às pesquisas e publicações, o modelo de pesquisa bibliográfica ganha ainda mais força, 
posto que a acessibilidade aos conteúdos específicos é de extrema facilidade.

Assim, o intuito da revisão integrativa, aqui, é a análise de pontos de convergência e divergência entre os estudiosos que se preocupam em abordar o tema de EDH, bem como a categorização de vários aspectos relevantes para o desenvolvimento de estratégias pedagógicas para o ensino em direitos humanos.

A escolha pela revisão bibliográfica integrativa pode ser expressa com a ideia de que "este método de pesquisa permite a síntese de múltiplos estudos publicados e possibilita conclusões gerais a respeito de uma particular área de estudo" (Mendes et al., 2008, p. 759). A partir da síntese dos pontos e conceitos mais utilizados, citados e expressos nas publicações de artigos fichadas foi possível a criação de um material fundamentado no que há de mais atual e específico sobre o tema.

Ademais, a escolha pelo método de revisão integrativa também está ligada ao fácil acesso de revistas que tratam, especificamente, do tema de interesse da pesquisa, que é a EDH. Embora a tarefa da combinação de dados de delineamento de pesquisas seja complexa e desafioadora, a revisão integrativa, por meio de "sistemática e rigorosa abordagem do processo, particularmente da análise de dados, resulta na diminuição de vieses e erros" (Souza et al. 2010, p. 105).

Foram analisadas publicações de artigos de uma das revistas voltadas para a Educação em Direitos Humanos, sendo ela a RIDH (Revista Interdisciplinar de Direitos Humanos) da UEMG. Também foram encontradas outras duas revistas, sendo elas: Revista Ciência em Movimento: Educação e Direitos Humanos, do Centro Universitário Metodista; a RIDH (Revista Interdisciplinar de Direitos Humanos), da UEMG, e a SCIAS Direitos Humanos e Educação, sendo esta última sem publicações até o presente momento da pesquisa.

A Revista Ciência em Movimento: Educação e Direitos Humanos foi descartada da revisão integrativa porque não possuia todas as edições disponíveis em seu site. $\mathrm{O}$ que culminou na decisão da análise de apenas uma revista, porém, compreendendo todos os artigos publicados pela revista até o presente momento.

A RIDH conta com publicações semestrais desde 2013, contendo 7 publicações até o presente momento da pesquisa. A revista também conta com publicações em formato de artigos, resenhas e dossiês. Todas as publicações em formato de artigo foram analisadas. $\mathrm{Na}$ apresentação da primeira edição da revista consta uma importante análise do panorama brasileiro acerca da construção científica em educação em direitos humanos.

A revisão bibliográfica desta pesquisa objetiva traçar, de maneira fundamentada, as percepções de diversos autores sobre a educação em direitos humanos, a visão da historicidade dos direitos humanos no Brasil e as conclusões dos autores no que diz respeito à passagem do conteúdo de direitos humanos para os estudantes do ensino médio por meio de estratégias. Foram utilizadas, essencialmente, partes do resumo, da introdução e dos resultados e conclusões dos artigos analisados para a coleta de informação, que foi feita com fichas de leitura.

Foram analisados 59 (cinquenta e nove) artigos das 7 (sete) edições da revista RIDH. A pesquisa se deu por meio de fichas de leitura e, posteriormente, gráficos com as informações coletadas.

Ressalta-se, aqui, que as percepções e dados coletados referem-se única e exclusivamente aos objetivos últimos da pesquisa realizada, podendo haver aspectos de extrema relevância para o assunto tratado no artigo mas que não foram levados em conta, posto que não acrescentavam contribuição para o resultado do trabalho. Cabe também salientar que todos os artigos foram lidos, analisados e fichados, mesmo aqueles que não se referem exatamente à $\mathrm{EDH}$ e, portanto, não continham propostas de estratégias de ensino. O intuito desta análise sumária é perceber como os direitos humanos são vistos por diversos autores, de diversas áreas de conhecimento, que se propõe a estudar e refletir sobre os conceitos e práticas atuais na área de direitos humanos. Também auxilia na análise de quais áreas mais se ocupam em tratar os direitos humanos.

\section{Apresentação e análise dos resultados}

Dos artigos lidos e analisados, 21 (vinte e um) trazem propostas de estratégias para a educação em direitos humanos. Há uma emergência no trato das questões dos direitos humanos que, por vezes, várias áreas de conhecimento se ocupam em tratar seus conceitos. Isso também pode ser notado a partir da quantidade de artigos que não tratam especificamente de estratégias para a educação em direitos humanos, exatamente porque é preciso, ainda, que os direitos humanos sejam tratados em diversas áreas de conhecimento sob diversos aspectos, posto que há ainda muita construção necessária para a produção científica do tema no Brasil. Também é essencial frisar que os direitos humanos perpassam por vários âmbitos da vida social, e por isso se dá a necessidade da transversalidade de seu ensino.

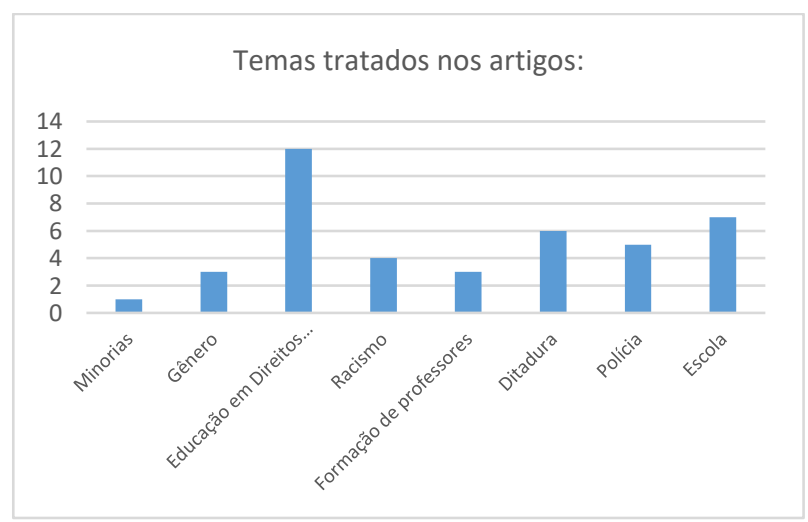

Gráfico 1.

Conforme o gráfico 1 acima, não há uma maioria esmagadora de artigos que tratem especificamente de Educação em Direitos Humanos em comparação com a soma dos temas dos demais artigos, o que, a priori, poderia ser considerado como uma lacuna para a produção da questão educativa em direitos humanos, porém isso se dá pela necessidade de abordar uma gama muito extensa de áreas de conhecimento dentro da questão dos direitos humanos. Ou seja, é necessário que sejam trazidos conhecimentos diversos na discussão para 
que se haja uma produção científica consistente e que esteja preocupada com a transformação do que é imposto e normalizado.

\section{Área de conhecimento dos} autores:

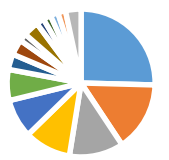

$\begin{array}{ll}\text { - Educação } & \text { - Direito } \\ \text { - Sociologia } & \text { - Direitos Humanos } \\ \text { - Filosofia } & \text { - História } \\ \text { - Relações Internacionais } & \text { - Psicologia } \\ \text { - Serviço Social } & \text { - Arquitetura } \\ \text { - Economia } & \text { - Comunicação Social }\end{array}$

\section{Gráfico 2.}

Como constatado no gráfico 2, a quantidade de áreas de conhecimento distintas que se preocupam com o tema direitos humanos nos certifica que o assunto não se esgota em questões específicas. Áreas de conhecimento como a Comunicação Social e Arquitetura e Urbanismo são alguns dos exemplos de como os direitos humanos perpassam muitos temas que vão além das matérias específicas.

Também destaca-se a expressiva quantidade de autores que se situam na área de conhecimento específica de Educação, conforme gráfico 2, o que demonstra que há, atualmente, uma preocupação maior com o assunto de $\mathrm{EDH}$, que também cresce como disciplina de pósgraduações por todo o Brasil, por exemplo.

\section{Quantidade de artigos por}

\section{ano:}

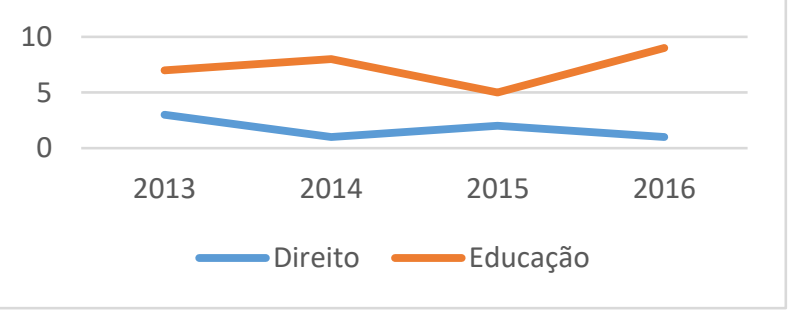

\section{Gráfico 3.}

Conforme disposto no gráfico 3 , há um aumento expressivo de publicações que tratam sobre a Educação enquanto há uma diminuição das publicações que tratam apenas dos aspectos jurídicos da questão. Essa constatação é de grande importância no que concerne o avanço dos direitos humanos como um assunto de relevância para a educação em várias instituições sociais. Os aspectos jurídicos, ainda, agregam muito ao estudo dos direitos humanos, por serem toda a fundamentação ao assunto, mas os direitos humanos conquistaram um lugar muito importante dentro da sociedade, e, por isso, é necessário que outras áreas do conhecimento se preocupem em estudar os seus conceitos.

Já no que concerne os asuntos tratados, separados por suas palabras-chave, foi realizada uma contagem das expressões e palavras mais utilizadas nas 59 publicações: Direitos humanos apareceram 22 (vinte e duas) vezes; Educação em Direitos Humanos, 8 (oito) vezes; violencia e democracia apareceram 5 (cinco) vezes; ditadura e educação, 4 (quatro) vezes; gênero, memória, dignidade da pessoa humana, movimentos sociais apareceram todas 3 (três) vezes; e por fim, religião, racismo, psicología, policía e diversidade apareceram 2 (duas) vezes.

É interessante perceber que as palavras "ditadura", "violência" e "democracia" só ficam atrás das palavras "educação" e "direitos humanos", que são as palavras que dão nome à Revista. A frequência com que as três primeiras palavras aparecem nas publicações pode estar atrelada às demandas atuais dos produtores de conhecimento. A democracia, a violência e a ditadura ainda são preocupações recorrentes no campo dos direitos humanos no Brasil e na América Latina, devido às ditaduras do continente, ao processo de redemocratização ainda recente e à ainda constante violência que resiste no seio desses países.

Logo depois, vemos que "gênero", "memória" e "movimentos sociais" também são preocupações recorrentes dentro dos direitos humanos. A questão de gênero é algo que os direitos humanos tentam, paulatinamente, corrigir. A memória, e principalmente o acesso à verdade dos fatos também é algo que preocupa a comunidade acadêmica de EDH, por ser necessária para o ensino de história e para a construção de indivíduos cientes do seu passado e sua historicidade. Os movimentos sociais são uma grande ferramenta na demanda de direitos civis, principalmente das minorias. No Brasil, o movimento negro, a comunidade LGBT e os movimentos feministas são grandes exemplos de movimentos sociais que dão voz às demandas de uma parcela marginalizada da sociedade.

O quadro nos auxilia na construção de estratégias iniciais para lidar com os direitos humanos porque mostra, de maneira clara, quais as preocupações mais colocadas em pauta por meio das construções teóricas.

\section{Percepção dos autores acerca da EDH}

Esse quesito é, talvez, o mais surpreendente de todos os resultados obtidos na revisão integrativa. A percepção dos autores no que tange a $\mathrm{EDH}$, ou apenas os direitos humanos, resultam em uma mentalidade horizontal. Não há, em todos os artigos lidos e fichados, qualquer faísca de pensamento que se alinhe ao senso comum de que direitos humanos são para apenas uma parte da população, definida por um comportamento específico. Há, no entanto, diversas opiniões distintas, umas mais críticas e outras um até um pouco utópicas.

Em 45 (quarenta e cinco) artigos, os autores se posicionam com a percepção de que a boa compreensão 
dos indivíduos sobre os direitos humanos - seja na EDH ou em outros projetos - podem auxiliar em uma matéria específica, como a psicologia, a sociologia e a pedagogia.

A percepção da contribuição dos direitos humanos nas diferentes áreas de conhecimento são inúmeras. Alguns dos exemplos são:

1. no combate à violência contra jovens negros no Brasil;

2. no acesso à verdade e memória dos acontecimentos históricos brasileiros;

3. na formação de professores e educadores;

4. na tentativa de humanização da polícia no Brasil;

5. na compreensão do direito à moradia;

6. na compreensão do direito ao acesso da cidade;

7. no combate à desigualdade de gênero;

8. assegurar a efetividade do Estado democrático de direito;

9. no combate à política punitiva;

10. na emancipação e conquista de direitos da comunidade LGBT.

\section{Considerações Finais}

A EDH é, perceptivelmente, um assunto de relevância na construção de estratégias pedagógicas e educativas no Brasil. Dessa forma, é preciso que as demandas sociais, que demonstram os aspectos a serem melhorados, sejam enxergadas à luz de um apanhado de fatos históricos que constituíram a história da educação até então. Por mais que haja um crescimento na percepção de que o entendimento dos direitos humanos seja importante para várias áreas de conhecimento, os conceitos usados para o assunto ainda carregam uma carga de rebuscamento linguístico que dificulta o acesso de muitas pessoas. Além disso, os direitos humanos ainda são muito recentes enquanto disciplina e ainda estão conquistando o seu devido lugar na produção científica.

No Brasil, ainda, há a expressiva força dos movimentos sociais, que auxiliam na conquista de muitos direitos, bem como no combate às violações aos direitos fundamentais. Os movimentos sociais devolvem voz à uma parcela destituída de fala e excluída socialmente por uma tradição histórica que deixa resquícios de desigualdade, violência e injustiça. Entretanto, o alcance dos movimentos sociais é limitado, assim como seu poder de persuasão em face à sociedade.

Cabe, então, à educação e suas formas pedagógicas, o dever de tentar promover senso crítico dos cidadãos para a transformação social e intervenção no mundo. Os instrumentos educacionais, quando usados objetivando romper com a ordem vigente, podem ser crucial para a mudança.

A revisão integrativa em $\mathrm{EDH}$ demonstra que existe uma preocupação crescente com os direitos humanos e com a aplicação dos seus conceitos nas instituições sociais. São várias as áreas de conhecimento que se apropriam de seus conceitos para legitimar suas teses e aprimorarem seus esforços. Como exemplo pode-se destacar a segurança pública, que se preocupa com o uso dos direitos humanos para alcançar uma maior humanização da polícia e, consequentemente, uma diminuição da violência policial.
Além disso, o fato de os direitos humanos estarem saindo do foco exclusivamente jurídico também é motivo para o maior interesse das demais áreas. $\mathrm{O}$ aparato jurídico é conhecido pelo seu rebuscado e único linguajar, que dificulta que toda a população seja contemplada na sua compreensão. $\mathrm{O}$ crescimento do estudo dos direitos humanos engloba uma interdisciplinaridade que é de grande importância para os avanços nas conquistas da área, sobretudo por ser um assunto que abrange um número extenso de elementos e pessoas.

A percepção dos autores sobre as matérias dos direitos humanos está alinhada com as demandas sociais, no sentido de que, os esforços das produções científicas são as mesmas preocupações que surgem de demandas sociais. No âmbito da EDH no Brasil, esse alinhamento é demonstrativo de que as publicações acadêmicas possuem um viés progressista que expressam preocupações sociais e visam a transformação social.

\section{Referências}

Benevides, Maria Victoria. Educação em direitos humanos: de que se trata. Formação de Educadores. Desafios e Perspectivas. S. Paulo: UNESP, p. 309-318, 2003.

Betto, Frei. Educação em direitos humanos. Revista Véspera. São Paulo, 1993.

Boff, Leonardo. Prefácio. In: FREIRE, Paulo. Pedagogia da Esperança. Paz e Terra, Rio de Janeiro, 1992.

Casiraghi, Bruna. Profissão docente: uma análise de seu significado tal como entendido nas revistas de educação mais consultadas no Brasil (1998-2008). 2010. 157 págs. Dissertação, Mestrado em Educação. PUC-SP.

Castells, Manuel. Redes de indignação e esperança: movimentos sócias na era da internet. Rio de Janeiro: Zahar, 2013.

Freire, Paulo. Pedagogia da Autonomia. Paz e Terra, Rio de Janeiro, 2015.

Gramsci, Antonio. Os intelectuais e a organização da cultura. Rio de Janeiro: Civilização Brasileira, 1968.

Mendes, Karina Dal Sasso; Silveira, Renata Cristina de Campos Pereira; Galvão, Cristina Maria. Revisão integrativa: método de pesquisa para a incorporação de evidências na saúde e na enfermagem. Texto contexto - enferm., Florianópolis, v. 17, n. 4, p. 758-764. http://www.scielo.br/scielo.php?script=sci_arttext\&pi $\mathrm{d}=$ S0104-07072008000400018\&lng=en\&nrm=iso

Mészaros, István. A Teoria da alienação em Marx. São Paulo: Boitempo, 2016.

Mészáros, István. Educação para além do capital. São Paulo: Boitempo, 2005.

Pereira, Maria Arleth. A Educação Brasileira e a L.D.B. In: RAYS, Oswaldo Alonso. Leituras para repensar a prática educativa. ${ }^{a}$ Edição, SAGRA, Porto Alegre, 1990.

Severino, Antônio Joaquim. Educação, sujeito e história. São Paulo: Olho D’água, 2001.

Souza, Marcela Tavares, SILVA, Michelly Dias e Carvalho, Rachel de. Revisão integrativa: o que é e como fazer. Einstein, 2010; 8(1 Pt 1): 102-6. 